\title{
A review on the complexity of insect-plant interactions under varying levels of resources and host resistance: the case of Myzus persicae-Prunus persica
}

\author{
Jaime A. Verdugo ${ }^{(1)}$, Frédéric Francis ${ }^{(2)}$, Claudio C. Ramírez ${ }^{(1)}$ \\ (1) Universidad de Talca. Instituto de Ciencias Biológicas. Centro en Ecología Molecular y Aplicaciones Evolutivas en \\ Agroecosistemas - Núcleo Milenio (CEM). Casilla 747. Talca (Chile). E-mail: clramirez@utalca.cl \\ (2) University of Liège - Gembloux Agro-Bio Tech. Agrobiochem. Functional and Evolutionary Entomology. Passage des \\ Déportés, 2. B-5030 Gembloux (Belgium).
}

Received on May 11, 2015 ; accepted on August 23, 2016.

Introduction. Insect-plant interactions are affected directly or indirectly by stress factors. The effect of environmental resource availability on insect-plant interactions is here reviewed. Subsequently, the analysis focuses on aphid-host plant interactions, particularly in the system composed by the green peach aphid Myzus persicae and its primary host plant Prunus persica.

Literature. Plant defenses arise in two ways: resistance and tolerance, both are affected by abiotic factors. The information gathered from studies $(n=29)$ on plant-aphid interactions addressing the reduction in water availability on plant resistance, showed that in $41,4 \%$ of the studies, drought stress elicits lower resistance, while $34.5 \%, 20.1 \%$ and $3.4 \%$, showed higher, no change and conditional effects on plant resistance, respectively.

Conclusions. Water stress elicits mixed effects on plant resistance to aphids. However, the literature review also suggests that cultural practices play a role in the fate of the peach-aphid interactions, whereas the development of predictive models aimed to assist crop-pest management systems still requires more basic information. Aphid responses to plant defenses under stressed conditions are still largely unexplored.

Keywords. Prunus persica, Myzus persicae, defense mechanisms, host pathogen relations, resistance to injurious factors, resources.

La complexité des interactions insectes-plantes en fonction de différents niveaux de ressources et de résistance de l'hôte : le cas de Myzus persicae-Prunus persica (synthèse bibliographique)

Introduction. Les interactions plantes-insectes sont influencées directement ou indirectement par plusieurs facteurs de stress. Dans cette synthèse bibliographique, l'effet de la disponibilité des ressources sur ces interactions est en premier lieu abordé au sens large, suivi d'une analyse ciblée des relations impliquant le modèle puceron, en particulier le puceron vert du pêcher Myzus persicae et son hôte principal, Prunus persica.

Littérature. Les défenses des plantes envers les insectes se manifestent de deux façons : la résistance et la tolérance, toutes deux influencées par des facteurs abiotiques. Les informations recueillies à partir d'études $(n=29)$ concernant l'effet de la diminution de la disponibilité en eau sur les défenses contre les insectes, ont montré que dans 41,4\% des études, le stress hydrique induit la résistance. Dans 34,5\%,20,1\% et 3,4\%, les effets sur la résistance étaient respectivement moindres, absents et conditionnels.

Conclusions. Le stress hydrique provoque des effets mitigés sur la résistance des plantes aux pucerons. Toutefois, la revue bibliographique suggère également un rôle des pratiques culturales dans les interactions pêcher-puceron, tandis que le développement de modèles prédictifs visant à assister les systèmes de gestion des bio-agresseurs nécessite la collecte de davantage de données.

Mots-clés. Prunus persica, Myzus persicae, mécanisme de défense, relation hôte pathogène, résistance aux facteurs nuisibles, ressources. 


\section{INTRODUCTION}

Insect-plant interactions are the result of co-evolutionary processes (Percy et al., 2004). The co-adaptation, co-evolution and co-speciation between herbivores and their host plants have been a central topic of modern biology in recent decades. These interactions have also been a relevant research topic, in various disciplines including animal behavior, physiology, genetics and chemistry (Scriber, 2002; Bruce, 2015). Insect-plant interactions occur in a complex scenario that includes varying levels of organization - from the cellular level to the community level (Kessler, 2006). One way to reduce the complexity is to distinguish key aspects of insect-plant relationships. These include the following processes:

- host plant recognition,

- plant response to insects,

- community ecology of herbivore-plant interactions

(natural enemies, competitors, diseases and mutualism),

- abiotic environmental factors that mediate insectplant interactions and generate geographic mosaics between insects and plants (Schoonhoven et al., 2005).

In this review, we focus on two of these processes: plant response to insects and abiotic environmental factors mediating these responses, focusing on aphidplant interactions.

\section{PLANT-INSECT INTERACTIONS: THE BIG PICTURE}

Host selection by phytophagous insects usually involves finding a host plant to feed on, to survive and develop (Schoonhoven et al., 2005). Host specialization by insects has led to a fine-tuned discrimination for the "correct" plant to feed on. Specifically, this task involves vision, olfaction, mechano-sensation and gustation. All these sensory systems help insects to select the "right" host plant by discriminating among shapes, sizes and colors. Vision interacts with olfaction because similar colors exist in a wide range of plants. The olfactive attraction to host plants is primarily mediated by volatiles (Bernays, 2001). Laboratory studies have shown that insects are both attracted and repelled by plant volatiles that differ between plants and plant parts, which are active during host selection. Aphids are attracted by visual cues, but volatiles from host plants are more important at short distances (Döring, 2014). Mechano-sensation and gustation are also elements of host recognition, and these can take place even without penetrating the surface of the plant (Powell et al., 2006). After the insects have reached their host plants, the plants do not behave as if nothing has happened. Instead, plants have developed a plethora of reactions that have been the subject of extensive research over the last decade (Barret et al., 2012).

From a bottom-up point of view, plant-insect interactions are highly dependent on the host quality, which is itself linked to biotic and abiotic factors, all of which affect the insect performances (Scriber et al., 1981; López-Carretero et al., 2014). A lack or excess of nutrients (e.g., nitrogen, water, $\left.\mathrm{CO}_{2}\right)$ and stress factors (e.g., heat, radiation) can alter these interactions. Indeed, an increased incidence of agricultural drought is expected to increase crop water stress (Lobell et al., 2012). In this context, the adaptation of insects to the nutritional level of plants has various implications depending on the insect life-cycles and their abilities to compensate for such deficits. These adaptations affect the rate of insect growth, survival time, and the number of generations in a growing season (Scriber et al., 1981; Mullins, 2015).

We will focus here on plant defense responses to insect attacks, emphasizing the effects of abiotic stresses and finally, address more in detail the system composed by the green peach aphid (Myzus persicae) and its primary host, the peach tree (Prunus persica).

\section{PLANT DEFENSE STRATEGIES TO THE ATTACKS BY HERBIVORES: RESISTANCE AND TOLERANCE}

In agricultural terms, resistance and tolerance denote plants that perform better than susceptible or nontolerant ones when having to face an insect pest infestation (Teetes, 1996). Resistance and tolerance are the two main forms of plant defense against the attacks from herbivores (Kariñho-Betancourt et al., 2015). These traits produce economic benefits by diminishing the need for insecticides to reduce pest populations. Resistance corresponds to chemical and physical mechanisms by which plants reduce herbivory (antibiosis) and/or insect preference (antixenosis) (Leimu et al., 2006), and can be divided into constitutive and induced resistance. While constitutive resistance is expressed independently of the attack, induced resistance arises immediately when the plant is attacked and damaged (Karban et al., 2007). A well-known example of this is the induction of cardenolides i.e. toxic glycosides by milkweed species (Asclepiadaceae) in response to attacks of monarch caterpillars (Danaus plexippus). The tolerance of plants to herbivory reflects the degree to which a plant can regrow and reproduce after damage from herbivores (Strauss et al., 1999). Tolerant responses have been modeled in several studies. The 
"compensatory continuum hypothesis", which is a way to model tolerance, predicts high tolerance to herbivory under conditions with high nutrient availability (water and fertilizer) versus lower tolerance in stressed environments with low nutrient availability; therefore, plant compensatory capability depends on external factors (Pirk et al., 2013). For example, individuals of the plant Ipomopsis arizonica supplemented with nutrients and growing free of competition produced more fruits when grazed than ungrazed control plants (Maschinski et al., 1989). Another model, the "limiting resource model", specifically considers which nonexclusive factors are limiting plant fitness and which resources are affected by particular herbivores (Wise et al., 2005). A good example of this is the effect of competition on tolerance of leaf damage (Wise et al., 2007). Other models highlight the relationship between tolerance and resistance. For instance, under some conditions of abiotic stress, plants may display trade-offs between resistance and tolerance, which may result in an inverse relationship between them (Stowe et al., 2000). An example of this is the inverse relationship between resistance to aphids and tolerance response in branch length in poplars (Ramírez et al., 2009). However, resistance and tolerance can occur simultaneously in species that display a mixed defense strategy in which the relative importance of resistance and tolerance largely depend on the availability of resources (Nuñez-Farfán et al., 2007). At the same time, there is the idea that resource allocation to growth, reproduction and defense are limited; plants allocating resources to defense will reduce their growth or reproduction rates, leading to the so-called "cost of defense" (Bergelson et al., 1996; Siemens et al., 2003). Higher costs of resistance are naturally expected in nutrient-poor habitat (Zangerl et al., 1992). Other theories, however, predict reduced costs of resistance in environments with limited resources (Herms et al., 1992). Bergelson et al. (1996) conducted research on the cost of resistance in herbaceous plants, detecting no consistent patterns from environmental effects on resistance costs. In woody plants, the costs of resistance are also influenced by the nutritional conditions of the soil (Prittinen et al., 2003). Furthermore, studies addressing how the environment affects costs of tolerance have revealed the presence of costs under stressful conditions and low nutrient availability (Hochwender et al., 2000) in dry and wet environments (Fornoni et al., 2004) and under favorable conditions (Siemens et al., 2003). In general, the ability to display tolerance should be reduced under conditions of limited resources availability (Nuñez-Farfán et al., 2007).

Most studies on resistance and tolerance focus on annual or short-lived perennial plants. This may result from the need to estimate the economic costs of pests on crops and forage plants, which are mostly herbaceous plants (Haukioja et al., 2000). Good examples in that respect for woody plants are provided by aspen (Populus tremuloides) as model. Studies on aspen have revealed that under a high nutrient quantity, resistance competes directly with growth, but not with tolerance (Stevens et al., 2007). While under drought stress, aphid resistance of Populus was reduced but its tolerance was enhanced (Ramírez et al., 2009). Among insects, aphids (Hemiptera: Aphididae) are sap-feeders and have been used as a model for several studies that show they have developed specialized strategies to overcome plant responses (Hopkins et al., 2009).

We will briefly review plant-aphid interactions, emphasizing plant resistance and responses to insect damage under the influence of abiotic factors, focusing on the complex interactions composed of the green peach aphid $M$. persicae and its primary host plant, the peach tree $P$. persica. First, we will address aphid-plant interactions in general, and then focus on the aphidpeach tree system.

\section{APHID-PLANT INTERACTIONS UNDER VARYING RESOURCE AVAILABILITY}

Aphids can adapt to environmental changes because of their flexible life cycles. They are resistant to a wide range of biotic (e.g., herbivore and pathogen damage) and abiotic (e.g., water deficit, high salinity, extremes of temperature, low nutrients) stresses through their physiological, behavioral and biochemical responses. However, because the population growth rate of aphids depends on the quality of food supply, abiotic stresses that affect plant traits such as nutrient and water content also affect aphid biology (Bale et al., 2007). As an example, Stafford et al. (2012) show the effect of fertilizers (organic animal manure and conventional fertilizers) on Brassica plants with two species of aphid, namely the Brassica specialist Brevicoryne brassicae and the generalist M.persicae. In this study, B. brassicae performed better in plants developed on organic manure, in contrast to M.persicae that performed better with conventional fertilizer. Therefore, performance does not only depend on the quality and type of food, but also on aphid species. On the other hand, the performance of aphids on woody plant stressed by polluted air is not affected, and does not trigger aphid outbreaks on plants (Holopainen, 2002).

Huberty et al. (2004) studied the responses of various guilds of insects feeding on water-stressed plants and showed that sap-feeders were negatively affected by continuous water stress, because it interferes with the herbivores' nitrogen supply. Alternatively, Khan et al. (2011) showed how water stress on broccoli plants (Brassica oleracea var. 'italica') resulted in the 
Verdugo J., Francis F. \& Ramirez C.

induction of some secondary metabolites, which may reduce aphid performance. However, the strength of the stress may also be important. For example, medium levels of water stress resulted in elevated fecundity and intrinsic rate of increase of B.brassicae and M. persicae on B. oleracea (Tariq et al., 2012). Water stress intensity may enhance or reduce both insect performance and plant resistance (Mody et al., 2009). For instance, continuous or pulse-water-stressed supply could entail different effects on aphids. Indeed, Huberty et al. (2004) reviewed several studies and concluded that pulse-stress is beneficial for sap-feeder. However, Simpson et al. (2012) explicitly tested the pulsed-stress hypothesis and showed that drought improved aphid population growth and survival. Although many studies are devoted to the effect of stress frequency, much less is known about the aphid response to these stresses beyond performance and survival. Interestingly, the proteome of aphids fed on stressed plants have revealed differential regulation of proteins associated with energy metabolism (Nguyen et al., 2007). Similarly, Verdugo et al. (2015) studied the proteomics profile of M.persicae fed on resistant and susceptible peach tree under water stress, and identified differentially regulated aphid's proteins associated either to energy metabolism, or to cytoskeleton function.

Table 1 lists a non-exhaustive search of studies concerning the relationships between drought stress and plant defenses in different aphid-plant models. Studies analyzed involved water stress treatments, which affected plant morphology, physiology and biochemistry (Anjum et al., 2011), which in turn could reduce or elevate the plant susceptibility to aphids (Mody et al., 2009). The information gathered from these studies $(n=29)$ showed that in $41,4 \%$ of the studies, drought stress elicits lower resistance, while $34.5 \%, 20.1 \%$ and $3.4 \%$, showed higher, no change or conditional effects on plant resistance, respectively. It is noteworthy that some plant species exhibit a range of variable drought-induced resistance traits that depend on the aphid species studied (e.g., barley; Table 1). Indeed, different studies using the same aphid-plant system exhibited opposite responses (see Arabidopsis green peach aphid interaction in table 1). Experimental factors such as level of drought, time of evaluation, aphid density, among others, need to be standardized to draw unambiguous conclusions about the effect of drought on plant resistance to aphids.

This partially supports, at least for aphids, the historical view that herbivorous insects exhibit elevated performance and outbreak dynamics on water-stressed plants (White, 1969). It should be considered that phloem-feeding insects exhibit poor performance on continuously stressed plants, which might exist in experimental conditions, whereas in natural conditions these insects may respond positively on intermittently stressed plants (Huberty et al., 2004).

\section{THE ATTACK OF MYZUS PERSICAE AND THE RESPONSES OF ITS PRIMARY HOST PRUNUS PERSICA}

The green peach aphid, Myzus persicae (Sulzer) (Hemiptera:Aphididae) is a generalist aphid species for which the peach tree, Prunus persica (Rosaceae) is its primary host but it also infests approximately 400 plants from different families as secondary hosts (Blackman et al., 2000). Myzus persicae is considered as a serious problem due to the wide spectrum of plant species it attacks and its ability to transmit plant viruses (Foster et al., 2008). In peach orchards, M.persicae can cause direct damage through sap collection by removing leave assimilates which once a certain level is reached results in shoot deformation, fall of fruits or flowers and weakening of the tree. Moreover it can generate indirect damage as the vector of Plum Pox Virus, which is the agent of Sharka disease (Manachini et al., 2007). A wide range of insecticide resistance mechanisms has also been reported for this aphid species (Bass et al., 2011). Myzus persicae is one of the most studied aphid species, although there are few studies that attempt to decipher the interaction between this aphid and its primary host $P$. persica. Instead, most studies are focused on its secondary hosts, as cabbage (Simpson et al., 2012) and broccoli (Khan et al., 2010; Khan et al., 2011), because of their major economic importance.

\section{MYZUS PERSICAE - PRUNUS PERSICA INTERACTIONS UNDER THE INFLUENCE OF GENETIC RESISTANCE AND CROPPING FACTORS}

Peaches and nectarines belong to the Rosaceae and are popular fruits grown worldwide in temperate zones. Prunus persica var. 'nectarina' (nectarine) is a mutant of P. persica (L.) Batsch (peach) lacking fuzzy skin whose origin is unknown. Studies of molecular markers have shown that peaches and nectarines belong to different genetic groups (Rojas et al., 2008). Because of continuous genetic improvement, peaches and nectarines have changed considerably from their original wild state. Among peaches and nectarines, new cultivars with better characteristics such as fruit quality traits emerge constantly. Unlike other fruit species, the commercial lifetime of peach or nectarine cultivars typically does not exceed 15 to 20 years; older cultivars become outdated relative to newer cultivars. The French Institut National de la Recherche Agronomique 
Aphid-peach tree interaction, plant resistance and water deficit

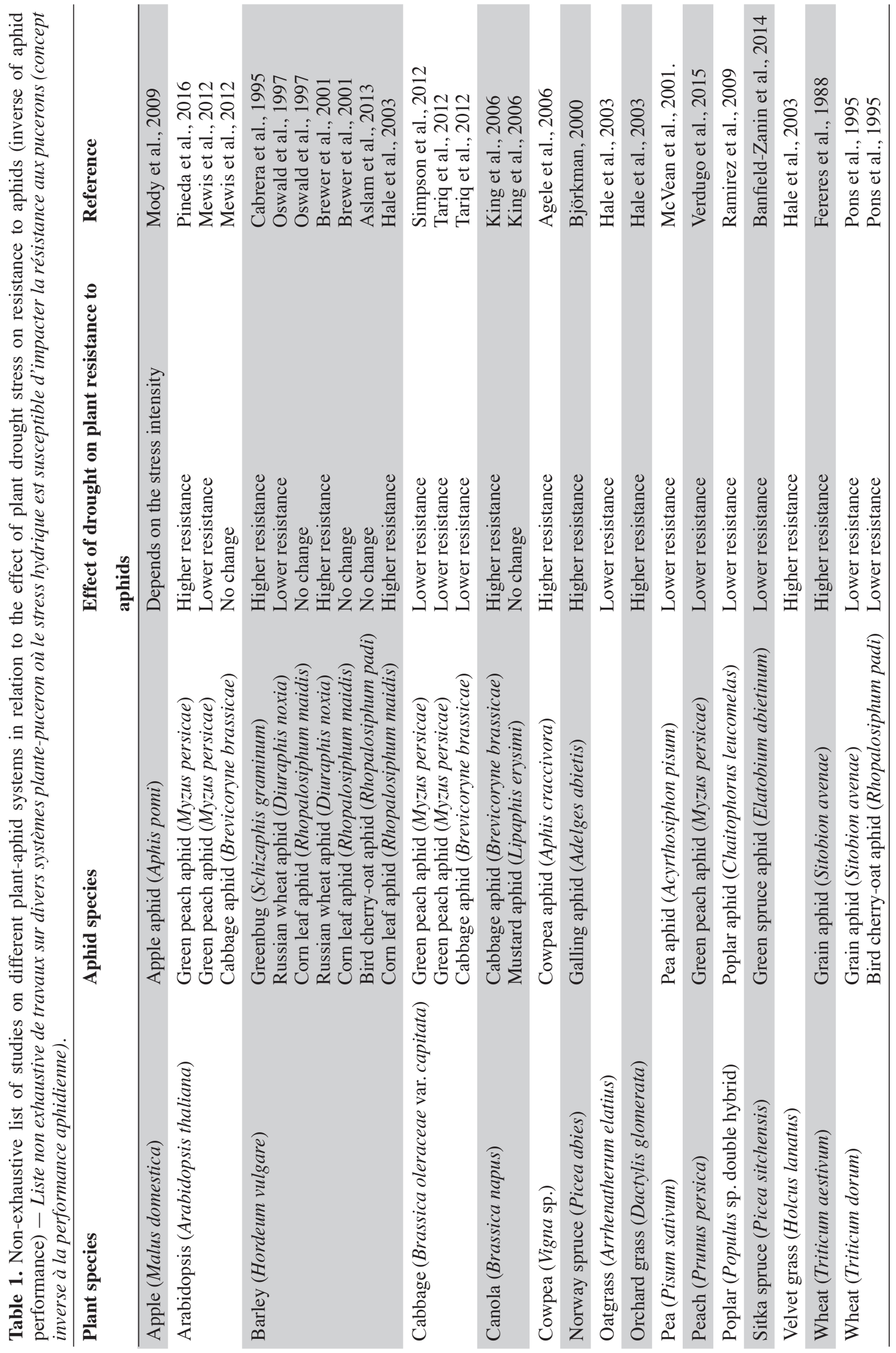


(INRA) developed programs to study peach resistance to various pests and diseases, including the resistance to M.persicae (Massonié et al., 1982; Lambert et al., 2011). The goals of these breeding programs were to reduce the need for insecticide applications and the resulting insecticide pollution as well as to select cultivars resistant to Sharka disease (Massonié et al., 1982; Monet et al., 1994). Thus, during the last three decades, several cultivars of P. persica, particularly 'Malo Konare', 'Weeping Flower Peach' and 'Rubira' but also wild species such as Prunus species as P.davidiana, P.cerasifera and P.kansuensis have been studied to characterize their resistance mechanisms. 'Malo Konare', cultivar from Bulgaria, displays antibiosis resistance (Sauge et al., 1998a). The resistance factors involved lead to reduced sap ingestion by the aphid, suggesting that they induced a change in the vascular system and sieve elements (Sauge et al., 1998b). 'Weeping Flower Peach', an ornamental peach cultivar native to America, and 'Rubira', a red-leaf cultivar from France commonly used as a rootstock, showed antixenosis resistance to $M$. persicae. In both cases, resistance is governed by a single dominant gene $R m 1$ and $R m 2$, respectively (Monet et al., 1994; Pascal et al., 2002; Lambert et al., 2011). Resistance in these two genotypes is associated with a hypersensitive-like response presenting reddish or yellowish dot necrotic reactions on leaves within a few days after colonization by aphids (Monet et al., 1994; Sauge et al., 1998b). In 'Rubira', the main resistance factor was found to be a constitutive degradation of substances in response to mechanical injuries and aphid salivary enzymes (Kfoury et al., 1995). Complementary works on 'Rubira' provided a detailed description of induced resistance. Infestation by a single aphid was sufficient to elicit a response $3 \mathrm{~h}$ after the beginning of the attack. Induced resistance remained effective until $48 \mathrm{~h}$ after infestation (Sauge et al., 2011).

The wild peach species P.davidiana exhibits a partial resistance to M.persicae. This species, originally from China, is closely related to P. persica. Resistance appeared to result from a phloematic sealing system that prevented aphid sustained sap uptake from the sieve elements (Sauge et al., 2004; CabreraBrandt et al., 2014). This resistance is governed by several QTLs (Sauge et al., 2012). The study of co-localization between the QTL of resistance and the QTL of aphid feeding behavior characterized by electropenetrography techniques show that the major QTL is associated with a drastic reduction in phloem sap ingestion, suggesting a phloem-based resistance mechanism. All these findings have enriched our understanding of the peach tree-aphid interactions; however further research is needed to investigate aphid responses to plant changes because these are key factors in understanding the short-term evolution of the system.

Two studies that investigated changes in peach metabolism upon $M$.persicae infestation have been performed. Staudt et al. (2010) provided evidence for the induction of volatile organic compound (VOC) emissions in these resistant peach genotypes, particularly methyl-salicylate. A metabolite profiling conducted by Poëssel et al. (2011) on 'Rubira' plants infested for $48 \mathrm{~h}$ by $M$. persicae established a decrease in carbohydrate levels, the accumulation of certain amino acids as well as of 3,5-dicaffeoylquinic acid, a phenolic compound with a possible impact on aphid performance. Along with the Prunus genotypes described before, genetic variation in susceptibility or resistance to $M$. persicae among commercial cultivars of peaches and nectarines has also been investigated. Those studies made it possible to identify resistance factors found to be located at prephloematic and phloematic level (Verdugo et al., 2012).

In addition to the on-going efforts to decipher peach resistance mechanisms, research on the impact of cultural practices (e.g., pruning, fertilization) on aphid attacks are also useful for pest control purposes. The effect of winter pruning and nitrogen availability on aphid abundance has been studied on peach trees. Grechi et al. (2008) showed that winter tree pruning modifies vegetative growth, thereby increasing $M$. persicae aphid populations without reducing fruit quality at the harvest. Sauge et al. (2010) studied the relationship between the performance of $M$. persicae and nitrogen supplies, and found that aphid population was reduced under both nitrogen shortages and overdoses. The information gathered from these studies can be useful to implement predictive models aimed to assist crop-pest management systems (Grechi et al., 2010; Grechi et al., 2012). To increase the predictive capacity of these models, further research on how the availability of resources mediates the $P$. persica-M. persicae interaction is needed.

Finally, a recent study reared M.persicae populations on well-watered and drought-stressed plants on both susceptible and resistant peach trees, and the effects of both stresses on aphid performance and proteomics were tested. Overall, the influence of the water treatments on aphid performance was less pronounced than the effect of host plant genetic resistance. On the susceptible cultivar, aphid survival, host acceptance and ability to colonize the plant did not depend on water treatment, whereas on the resistant cultivar, aphid survival and ability to colonize were higher on drought-stressed (lower resistance) than on well-watered plants (Verdugo et al., 2015). Thus, in this system, the historical view that herbivorous insects exhibit elevated performance and outbreak dynamics on water-stressed plants is supported. 


\section{CONCLUSIONS}

Plant-insect interactions have been discussed here from the point of view of plant defense mechanisms under aphid attacks, specifically considering peach tree-aphid interaction. Plants under drought stress appear to elicit mixed effects on resistance to aphids, with a slightly higher frequency of studies showing reduced resistance to aphids. Recent studies show that this is not the case for M.persicae-P. persica system. It remains to unravel the mechanism by which resources availability can improve or diminish plant susceptibility and resistance to aphid damage. This topic will be a significant issue of future studies to enlarge our understanding of plant resistance under changing resource-supply conditions as a consequence of climate change.

\section{Acknowledgements}

The authors are grateful to Julien Bauwens for the valuable help in the French translation. This research was partially supported by Fondecyt Grant 1100746, Iniciativa Científica Milenio grant NC120027, PhD Grant from the Facultad de Ciencias Agrarias of the Universidad de Talca awarded, Grant Becas Chile Conicyt-Chile, Grant of Communauté française de Belgique and the Région Wallonne, and to the Unité et Systèmes de culture Horticoles of INRA-Avignon, France.

\section{Bibliography}

Agele S.O., Ofuya T.I. \& James P.O., 2006.Effects of watering regimes on aphid infestation and performance of selected varieties of cowpea (Vigna unguiculata L. Walp) in a humid rainforest zone of Nigeria. Crop Prot., 25, 73-78.

Anjum S.A. et al., 2011. Morphological, physiological and biochemical responses of plants to drought stress. Afr. J. Agric. Res., 6, 2026-2032.

Aslam T.J., Johnson S.N. \& Karley A.J., 2013. Plant-mediated effects of drought on aphid population structure and parasitoid attack. J. Appl. Entomol., 137, 136-145.

Bale J.S., Ponder K.L. \& Pritchard J., 2007. Coping with stress. In: Van Emden H.F. \& Harrington R., eds. Aphids as crop pest. London: CABI Publishing, 287-303.

Banfield-Zanin J.A. \& Leather S.R., 2014. Frequency and intensity of drought stress alters the population size and dynamics of Elatobium abietinum on Sitka spruce. Ann. Appl. Biol., 165, 260-269.

Barret L. \& Heil M., 2012. Unifying concepts and mechanisms in the specificity of plant-enemy interactions. Trends Plant Sci., 17, 282-292.

Bass C. et al., 2011. Mutation of a nicotinic acetylcholine receptor beta subunit is associated with resistance to neonicotinoid insecticides in the aphid Myzus persicae. BMC Neurosci., 12, 51.

Bergelson J. \& Purrington C.B., 1996. Surveying patterns in the cost of resistance in plants. Am. Nat., 148, 536-558.
Bernays E., 2001. Neural limitations in phytophagous insects: implications for diet breadth and evolution of host affiliation. Annu. Rev. Entomol., 46, 703-727.

Björkman C., 2000. Interactive effects of host resistance and drought stress on the performance of a gall-making aphid living on Norway spruce. Oecologia, 123, 223-231.

Blackman R.L. \& Eastop V.F., 2000. Aphids on the world's crops: an identification guide. $2^{\text {nd }}$ ed. Chichester, UK: Wiley.

Brewer M.J. \& Webster J.A., 2001. Probing behavior of Diuraphis noxia and Rhopalosiphum maidis (Homoptera: Aphididae) affected by barley resistance to D. noxia and plant water stress. Environ. Entomol., 30, 1041-1046.

Bruce T.J.A., 2015. Interplay between insects and plants: dynamic and complex interactions that have coevolved over millions of years but act in milliseconds. J. Exp. Bot., 66, 455-465.

Cabrera H.M., Argandona V.H., Zuniga G.E. \& Corcuera L.J., 1995. Effect of infestation by aphids on the water status of barley and insect development. Phytochemistry, 40, 10831088.

Cabrera-Brandt M.A. et al., 2014. Intra-specific variation of behavioral signals in suppressing plant defenses in the green peach aphid Myzus persicae, feeding on the resistant wild peach Prunus davidiana. J. Pest. Sci., 88, 259-266.

Döring T., 2014. How aphids find their host plants, and how they don't. Ann. Appl. Biol., 165, 3-26.

Fereres A., Gutierrez C., Del Estal P. \& Castañera P., 1988. Impact of the English grain aphid, Sitobion avenae (F.) (Homoptera: Aphididae), on the yield of wheat plants subjected to water deficits. Environ. Entomol., 17, 596602.

Fornoni J., Valverde P.L. \& Nuñez-Farfan J., 2004. Population variation in the cost and benefit of tolerance and resistance against herbivory in Datura stramonium. Evolution, 58, 1696-1704.

Foster S.P. et al., 2008. Correlated responses to neonicotinoid insecticides in clones of the peach-potato aphid, Myzus persicae (Hemiptera: Aphididae). Pest Manage. Sci., 64, 1111-1114.

Grechi et al., 2008. How does winter pruning affect peach tree-Myzus persicae interactions?, Entomol. Exp. Appl., 128, 369-379.

Grechi et al., 2010. Modelling coupled peach tree-aphid population dynamics and their control by winter pruning and nitrogen fertilization. Ecol. Model., 221, 2363-2373.

Grechi I. et al., 2012. Designing integrated management scenarios using simulation-based and multi-objective optimization: application to the peach tree-Myzus persicae aphid system. Ecol. Model., 246, 47-59.

Hale B.K., 2003. Effects of host plant drought stress on the performance of the bird cherry-oat aphid, Rhopalosiphum padi (L.): a mechanistic analysis. Ecol. Entomol., 28, 666677.

Haukioja E. \& Koricheva J., 2000. Tolerance to herbivory in woody vs. herbaceous plants. Evol. Ecol., 14, 551-562. 
Herms D.A. \& Mattson W.J., 1992. The dilemma of the plants to growth or defend? Quart. Rev. Biol., 67, 478-478.

Hochwender C.G., Fritz R.S. \& Orians C.M., 2000. Using hybrid systems to explore the evolution of tolerance to damage. Evol. Ecol., 14, 509-521.

Holopainen J.K., 2002. Aphid response to elevated ozone and $\mathrm{CO}_{2}$. Entomol. Exp. Appl., 104, 137-142.

Hopkins R.J., van Dam N.M. \& van Loon J.J.A., 2009. Role of glucosinolates in insect-plant relationships and multitrophic interactions. Ann. Rev. Entomol., 54, 57-83.

Huberty A.F. \& Denno R.F., 2004. Plant water stress and its consequences for herbivorous insects: a new synthesis. Ecology, 85, 1383-1398.

Karban R. \& Baldwin I.T., 2007. Induced responses to herbivory. Chicago, IL, USA: University of Chicago Press.

Kariñho-Betancourt E. \& Nuñez-Farfán J., 2015. Evolution of resistance and tolerance to herbivores: testing the trade-off hypothesis. PeerJ, 3:e789.

Kessler A., 2006. Plant-insect interactions in the era of consolidation in biological sciences. Nicotiana attenuata as an ecological expression system. In: Dicke M. \& Takken W.,eds. Chemical ecology: from gene to ecosystem. Wageningen, The Netherlands: Springer, 19-37.

Kfoury L. \& Massonie G., 1995. Characteristics of the resistance of the peach cultivar Rubira to Myzus persicae Sulzer. Agronomie, 15, 277-284.

Khan M.A., Ulrichs C. \& Mewis I., 2010. Influence of water stress on the glucosinolate profile of Brassica oleracea var. italica and the performance of Brevicoryne brassicae and Myzus persicae. Entomol. Exp. Appl., 137, 229-236.

Khan M.A., Ulrichs C. \& Mewis I., 2011. Water stress alters aphid-induced glucosinolate response in Brassica oleracea var. italica differently. Chemoecology, 21, 235-242.

King C., Jacob H.S. \& Berlandier F., 2006. The influence of water deficiency on the relationship between canola (Brassica napus L.), and two aphid species (Hemiptera: Aphididae), Lipaphis erysimi (Kaltenbach) and Brevicoryne brassicae (L.). Aust. J. Agric. Res., 57, 439445.

Lambert P. \& Pascal T., 2011. Mapping Rm2 gene conferring resistance to the green peach aphid (Myzus persicae Sulzer) in the peach cultivar 'Rubira ${ }^{\circledR}$ '. Tree Genet. Genomes, 7, 1057-1068.

Leimu R. \& Koricheva J., 2006. A meta-analysis of tradeoffs between plant tolerance and resistance to herbivores: combining the evidence from ecological and agricultural studies. Oikos, 112, 1-9.

Lobell D.B. \& Gourdji S.M., 2012. The influence of climate change on global crop productivity. Plant Physiol., 160, 1686-1697.

López-Carretero A., Díaz-Castelazo C., Boege K. \& RicoGray V., 2014. Evaluating the spatio-temporal factors that structure network parameters of plant-herbivore interactions. PLoS One, 9(10), e110430.

Manachini B., Casati P., Cinanni L. \& Bianco P., 2007. Role of Myzus persicae (Hemiptera : Aphididae) and its secondary hosts in plum pox virus propagation. J. Econ. Entomol., 100, 1047-1052.

Maschinski J. \& Whitham T.G., 1989. The continuum of plantresponses to herbivory - The influence of plant association, nutrient availability and timing. Am. Nat., 134, 1-19.

Massonié G., Maison P., Monet R. \& Grasselly C., 1982. Resistance to green peach aphid Myzus persicae Sulzer (Homoptera, Aphididae) in Prunus persica (L.) Batsch and others Prunus. Agronomie, 2, 63-70.

McVean R.I.K. \& Dixon A.F.G., 2001. The effect of plant drought-stress on populations of the pea aphid Acyrthosiphon pisum. Ecol. Entomol., 26, 440-443.

Mewis I. et al., 2012. Water stress and aphid feeding differentially influence metabolite composition in Arabidopsis thaliana (L.). PLoS One, 7, e48661.

Mody K., Eichenberger D. \& Dorn S., 2009. Stress magnitude matters: different intensities of pulsed water stress produce non-monotonic resistance responses of host plants to insect herbivores. Ecol. Entomol., 34, 133-143.

Monet R. \& Massonié G., 1994. Déterminisme génétique de la résistance au puceron vert (Myzus persicae) chez le pêcher. Résultats complémentaires. Agronomie, 14, 177-182.

Mullins D., 2015. Physiology of environmental adaptations and resource acquisition in cockroaches. Annu. Rev. Entomol., 60, 473-492.

Nguyen T.T.A., Michaud D. \& Cloutier C., 2007. Proteomic profiling of aphid Macrosiphum euphorbiae responses to host-plant-mediated stress induced by defoliation and water deficit. J. Insect Physiol., 53, 601-611.

Nuñez-Farfán J., Fornoni J. \& Valverde P., 2007. The evolution of resistance and tolerance to herbivores. Ann. Rev. Ecol. Evol. Syst., 38, 541-566.

Oswald C.J. \& Brewer M.J., 1997. Aphid-barley interactions mediated by water stress and barley resistance to Russian wheat aphid (Homoptera: Aphididae). Environ. Entomol., 26, 591-602.

Pascal T. et al., 2002. Inheritance of green peach aphid resistance in the peach cultivar 'Rubira'. Plant Breeding, 121, 459-461.

Percy D.M., Page R.D. \& Cronk Q.C., 2004. Plant-insect interactions: double-dating associated insect and plant lineages reveals asynchronous radiations. Syst. Biol., 53, 120-127.

Pineda A. et al., 2016. Negative impact of drought stress on a generalist leaf chewer and a phloem feeder is associated with, but not explained by an increase in herbivore-induced indole glucosinolates. Environ. Exp. Bot., 123, 88-97.

Pirk G.I. \& Farji-Brener A.G., 2013. Can the nutrient-rich soil patches created by leaf-cutting ants favor plant compensation for foliar damage? A test of the compensatory continuum hypothesis. Plant Ecol., 214, 1059-1070.

Poëssel J.L. et al., 2011. Metabolite profiling and feeding bioassays suggest a major role for a dicaffeoylquinic acid in induced resistance of peach to Myzus persicae aphid. In: Proceedings of the International workshop PR-proteins and induced resistance against pathogens and insects, 4-8 
September 2011, Université de Neuchâtel, Switzerland, 54.

Pons X. \& Tatchell G.M., 1995. Drought stress and cereal aphid performance. Ann. Appl. Biol., 126, 19-31.

Powell G., Tosh C.R. \& Hardie J., 2006. Host plant selection by aphids: behavioral, evolutionary, and applied perspectives. Annu. Rev. Entomol., 51, 309-330.

Prittinen K., Pusenius J., Koivunoro K. \& Roininen H., 2003. Genotypic variation in growth and resistance to insect herbivory in silver birch (Betula pendula) seedlings. Oecologia, 137, 572-577.

Ramírez C.C. \& Verdugo J.A., 2009. Water availability affects tolerance and resistance to aphids but not the trade-off between the two. Ecol. Res., 24, 881-888.

Rojas G. et al., 2008. Identification of a minimal microsatellite marker panel for the fingerprinting of peach and nectarine cultivars. Electron. J. Biotechnol., 11(5).

Sauge M.-H., Kervella J. \& Pascal T., 1998a. Settling behaviour and reproductive potential of the green peach aphid Myzus persicae on peach varieties and a related wild Prunus. Entomol. Exp. Appl., 89, 233-242.

Sauge M.-H.,Kervella J.\& Rahbe Y., 1998b. Probing behaviour of the green peach aphid Myzus persicae on resistant Prunus genotypes. Entomol. Exp. Appl., 89, 223-232.

Sauge M.-H. et al., 2004. Mapping of a genetic factor of partial resistance to Myzus persicae in the wild peach Prunus davidiana, that impedes phloem sap ingestion by the aphid. In: Simon J.C., Dedryver C.A., Rispe C. \& Hulle M., eds. Aphids in a new millennium. Versailles, France : INRA Éditions, 499-505.

Sauge M.-H., Grechi I. \& Poessel J.L., 2010. Nitrogen fertilization effects on Myzus persicae aphid dynamics on peach: vegetative growth allocation or chemical defence? Entomol. Exp. Appl., 136, 123-133.

Sauge M.-H., Poessel J.L., Guillemaud T. \& Lapchin L., 2011. Resistance induction and herbivore virulence in the interaction between Myzus persicae (Sulzer) and a major aphid resistance gene $(\mathrm{Rm} 2)$ from peach. Arthropod-Plant Interact., 5, 369-377.

Sauge M.-H., Lambert P. \& Pascal T., 2012. Co-localisation of host plant resistance QTLs affecting the performance and feeding behaviour of the aphid Myzus persicae in the peach tree. Heredity, 108, 292-301.

Schoonhoven L.M., van Loon J.J.A. \& Dicke M., 2005. Insectplant biology. $2^{\text {nd }}$ ed. Oxford, UK: Oxford University Press.

Scriber J.M., 2002. Evolution of insect-plant relationships: chemical constraints, coadaptation, and concordance of insect/plant traits. Entomol. Exp. Appl., 104, 217-235.

Scriber J.M. \& Slansky F. Jr., 1981. The nutritional ecology of immature insects. Annu. Rev. Entomol., 26, 183-211.

Siemens J.A. \& Zwiazek J.J., 2003. Effects of water deficit stress and recovery on the root water relations of trembling aspen (Populus tremuloides) seedlings. Plant Sci., 165, 113120.

Simpson K.L.S., Jackson G.E. \& Grace J., 2012. The response of aphids to plant water stress - the case of Myzus persicae and Brassica oleracea var. capitata. Entomol. Exp. Appl., 142, 191-202.

Smith C.M. \& Boyko E.V., 2007. The molecular bases of plant resistance and defense responses to aphid feeding: current status. Entomol. Exp. Appl., 122, 1-16.

Stafford D.B. et al., 2012. Opposing effects of organic and conventional fertilizers on the performance of a generalist and a specialist aphid species. Agric. For. Entomol., 14, 270-275.

Staudt et al., 2010. Volatile organic compound emissions induced by the aphid Myzus persicae differ among resistant and susceptible peach cultivars and a wild relative. Tree Physiol., 30, 1320-1334.

Stevens M.T., Waller D.M. \& Lindroth R.L., 2007. Resistance and tolerance in Populus tremuloides: genetic variation, costs, and environmental dependency. Evol. Ecol., 21, 829847.

Stowe K.A., Marquis R.J., Hochwender C.G. \& Simms E.L., 2000. The evolutionary ecology of tolerance to consumer damage. Ann. Rev. Ecol. Syst., 31, 565-595.

Strauss S.Y.\& Agrawal A.A., 1999. The ecology and evolution of plant tolerance to herbivory. Trends Ecol. Evol., 14, 179185.

Tariq M., Wright D.J., Rossiter J.T. \& Staley J.T., 2012. Aphids in a changing world: testing the plant stress, plant vigour and pulsed stress hypotheses. Agric. For. Entomol., 14, 177-185.

Teetes G.L., 1996. Plant resistance to insects: a fundamental component of IPM. In: Radcliffe's IPM World Textbook. St. Paul, MN, USA: University of Minnesota, http://ipmworld. umn.edu/teetes (09/26/2016).

Verdugo J.A. et al., 2012. Variation in resistance mechanisms to the green peach aphid among different Prunus persica commercial cultivars. J. Econ. Entomol., 105, 1844-1855.

Verdugo J.A. et al., 2015. Drought-stress and plant resistance affect herbivore performance and proteome: the case of the green peach aphid Myzus persicae (Hemiptera: Aphididae). Physiol. Entomol., 40, 265-276.

White T.C.R., 1969. An index to measure weather-induced stress of trees associated with outbreaks of psyllids in Australia. Ecology, 50, 905-909.

Wise M.J. \& Abrahamson W.G., 2005. Beyond the compensatory continuum: environmental resource levels and plant tolerance of herbivory. Oikos, 109, 417-428.

Wise M.J. \& Abrahamson W.G., 2007. Effects of resource availability on tolerance of herbivory: a review and assessment of three opposing models. Am. Nat., 169, 443454.

Zangerl A.R. \& Bazzaz F.A., 1992. Theory and pattern in plant defense allocation. In: Fritz R. \& Simms E.L., eds. Plant resistance to herbivores and pathogens. Chicago, IL, USA: University of Chicago Press, 363-392.

Zhang P.J. et al., 2008. Trade-offs between constitutive and induced resistance in wild crucifers shown by a natural, but not an artificial, elicitor. Oecologia, 157, 83-92.

(87 ref.) 